\title{
Salient factors identification in head and neck cancer survival
}

\section{Diego Liberati* \\ Politecnico di Milano University, Italy}

Some 20 years ago head and neck cancer were still considered as a rare tumour: nowadays Lisa, our bright physician co-author in an article [1], is director of a deputy structure at National Cancer Institute in Milano. In Drago GP et al's [1] article we were trying to asses radiochemistry as yet not consolidated protocol. To do that, as a by-product we were able to prune the whole set of the traditionally measured data in every subject, showing that the 11 factors reported in figure 1 (taken from [1]) were sufficient not only to discriminate output but also to improve signal to noise ratio with respect to the use of all the data set: being world not linear, it was and it is not in generally true that more are the data, more is the info: often too not specific data hidden the very core of the underlying process. Not surprising, the most salient factor is the easiest one to measure without instruments, felt by good physicians on the basis of the general dynamical aspect of the patient: in fact, a popular say says that the main prognostic factor is the physician caring for you, embedding in almost a joke both the notion of competence and empathy. A not so different joke, dear to a former scientific director of Italian Cancer Institute in Milano, is that if you get in, even with just a cold (phopehtic, seen from nowadays :) you could get only get out horizontal! Other factors are pretty obvious, we will not discuss them here. Radio chemio is nowadays standard: better than just chemio after the most possibly radical surgery.

Somebody still thinks that no chemio is often even better. A friend neurosurgeon, whose name didi promiss not ti cite, thus take il like a further joke was gamma knife treating brain metastasis from the apparently same tumor in a pair of married patients. One got

\begin{tabular}{l|l}
\hline Salient Input & \\
\hline 1 & Performance Status \\
4 & Smoking \\
6 & Tumor stage \\
12 & Body Mass Index \\
15 & Platelets (PLT) \\
19 & Uric acid \\
22 & Plasmatic K \\
28 & Pseudo-Cholinesterase (CHE) \\
29 & Total Bilirubine \\
31 & Prothrombine Time (percent) (PT) \% \\
37 & Immunoglobulin G (IgG) \\
\hline
\end{tabular}

Figure 1. Traditionally measured data in every subject

chemio within the protocol of the hospital. The other didn't: hospital had no more budget fr that year: this last survived. The neurosurgeon refused chemio for his father who survived to a kindey tumor. Even consolidate protocols maybe deserve to be re-discussed even hoping in total absence of interest in their definition, as the present coronavirus apparent emergence would also suggests.

\section{References}

1. Drago GP, Setti E, Licitra L, Liberati D (2002) Forecasting the performance status of head and neck cancer patient treatment by an interval arithmetic pruned perceptron. IEEE Transactions Biomedical Engineering 49: 782-787.
Copyright: (C2020 Liberati D. This is an open-access article distributed under the terms of the Creative Commons Attribution License, which permits unrestricted use, distribution, and reproduction in any medium, provided the original author and source are credited.
${ }^{\star}$ Correspondence to: Diego Liberati, Politecnico di Milano University, Italy, Tel: +3902 23991; E-mail: diego.liberati@polimi.it

Received: February 18, 2020; Accepted: February 26, 2020; Published: February 28,2020 